\title{
Threshold Cointegration and Nonlinear Causality test between Inflation Rate and Repo Rate
}

\author{
Katleho Makatjane*, Ntebogang Moroke, Diteboho Xaba \\ North West University, South Africa \\ *katleho.makatjane@outlook.com
}

\begin{abstract}
The current study investigated a cointegration and nonlinear causality relationships between inflation and repo rates of South Africa using the data spanning the period of January 2002 to March 2016. We used a threshold vector error correction model (TVECM) and nonlinear Granger frameworks causality to carry out the analysis. Preliminary analysis of data revealed the expected properties of the data such as nonlinearity, non-stationarity and co-movement of the variables. The two variables confirmed to be moving together in the long-run according to the observed supWald test statistic. Finally, the Diks-Panchenko nonlinear Causality test revealed a strong bidirectional nonlinear causal relationship between repo rate and inflation rate. The results imply that the use of repo rate to target the inflation rate during the target period did not address the financial problem in South Africa. Consequently, the study concluded that repo rate may not be a good measure to use for controlling inflation rates of South Africa.
\end{abstract}

Keywords: Threshold Cointegration, nonlinear causality test, financial data

\section{Introduction}

There is a general impression about the presence of a linear relationship between macroeconomic variables and as such most of the empirical studies base their analysis disregarding the fact that these variables may be nonlinear (Enders and Siklos, 2001; Iyke, 2015). Empirical Studies by among others Granger and Lee (1989) and Balke and Fomby (1997) found that most of the macroeconomic variables correlate asymmetrically towards equilibrium. As such, it is noteworthy to pay attention when subjecting these variables, specifically those of financial sector to the analysis to avoid reporting misleading findings that will influence policy decisions negatively. The current study proposes the application of asymmetric cointegration and nonlinear causality to inflation and repo rates of South Africa. This study explores the threshold vector error correction method (TVECM) Johansen cointegration and follows up with a Diks and Panchenko (2006) nonparametric nonlinear causality test. The Diks and Panchenko (2006)causality method lessens the biasness and hampers the risk of over-rejection of the null hypothesis according to (Karagianni et al., 2013). The study contributes to academic paradigm by filling a void in practical literature by instantaneously navigating error correction modelling and causality tests focusing on an asymmetric viewpoint. Such studies are very scares in literature as far as South Africa is concerned. There is evidence of studies that used other cointegration methods on inflation rates and other macroeconomic variablesespecially linear methods but evidence of studies on this sector and repo rate with the application of nonlinear methods has not been recorded. For more readings on nonlinear causality also see Nazlioglu et al. (2014), Bal and Rath (2015) and Phiri (2016).

The South African Reserve Bank has in February 2002 grasped a landmark as far as monetary policy conduct is concerned about becoming the first Bank in Central Africa to implement an inflation targeting regime. The bank set an inflation targets between $3 \%$ to $6 \%$ percent. This formed the spine of monetary policy conduct in South Africa. The objective of this policy was re-enforced by the constitution act of 1996 (Act No. 108) and was further enforced by the SARB Act No. 90 of 1989 (Iyke, 2015). The bank hoped to attain lower and stable inflation rates when implementing this strategy. This was also to avoid high prices resulting from high inflation rates and to ensure that resources are allocated accordingly (Hodge, 2009). High rates of inflation are also associated with issues such as reduced international competitiveness resulting in expensive exports (Gokal and Hanif, 2004; interference on the tax system which falsifies borrowing and lending decisions within the economy (Papepetrou, 2001). Eita and Jordan (2010) are of a view that "a financial sector is an important tool as far as transfer of deposits into financial assets and directing funds from surplus units to deficits is concerned". This consequently helps in facilitating and creating wealth trade and capital formation. The current study approach deviates from the norm of earlier studies directed to the South African economy. Most studies rely on linear relationship assumption between financial expansion and other macroeconomic variables. Some of the previous studies that estimated the South African inflation thresholds were conducted by Leshoro (2012) and Adusei (2012) respectively. 


\section{Literature Review}

The concept of cointegration was introduced by Granger and Lee (1989). This concept turned into a fundamental stride in the analysis of nonstationary time series. Regardless of the assumption that two or more variables are nonstationary, there exist a possibility that their combination is stationary(Esso, 2010).This definition prompts intriguing translations as the variables can then be interpreted to have a stable relationship (a long-run relationship), i.e. can be represented in a VECM, and share a typical stochastic pattern. Due to some adjustment costs, the conventional linear cointegration model and linear vector error correction model (VECM) might be inappropriate for testing the present-value model in the long run. To resolve this mystery, several financial and macroeconomic analysts introduced nonlinear models. Stigler (2010)among others recommended TVECM framework as it caters for nonlinear financial data. This cointegration method was first introduced by Balke and Fomby (1997) as a feasible approach to address nonlinearity. The method further captures asymmetries in the adjustment, where positive or negative deviations will not be corrected in the same manner. According to Hansen and Seo (2002), the model has produced remarkable associated enthusiasm, including the accompanying applications (Baum et al., 2001; Lo and Zivot, 2001; Taylor, 2001). In exploring nonlinear cointegration between the price of the international crude oil and stock market of India, Ghosh and Kanjilal (2016) employed a TVECM cointegration method. Along-run equilibrium relationship among the variables for the entire data was rejected. Surprisingly, TodaYamamoto Granger causality test revealed an impact of the international crude oil price movement on the Indian stock market with no feedback effect.

Ghassan and Banerjee (2015), analyzed the organization of petroleum exporting countries (OPEC) and nonOPEC crude oil dynamics using threshold cointegration method. While capturing the asymmetry of the long run, the authors developed an error correction model within a threshold cointegration and component generalized autoregressive conditional heteroscedasticity (CGARCH) framework.The study recorded cointegrating relations between OPEC price and non-OPEC prices. Also exhibited was the conditional volatility of variance with long run memory feature. The shocks on the long run component did not adjust quickly. In examining the causal relationship between energy consumption and economic growth for a sample of Asian newly industrialized countries as well as the United States (US), Chiou-Wei et al. (2008) applied both linear and nonlinear Granger causality tests. The study revealed an evidence supporting a neutrality hypothesis for the US, Thailand and South Korea. Nevertheless, empirical evidence on Philippines and Singapore disclosed unidirectional causality running from economic growth to energy consumption while energy consumption may have affected economic growth for Taiwan.

Diks and Wolski (2015), opined that Diks and Panchenko (2006) nonlinear Granger causality testing, which aims to correct for the over-rejection problem observed in the original methodology developed by Hiemstra and Jones (1994) has the problem with data sharpening. To correct that, Diks and Wolski replaced the correlation integral by the Gaussian kernel density estimator in assuring the performance of the Gaussian estimator.The authors first checked the behavior in the standard bivariate case and later extended the analysis into the multivariate setting by providing the asymptotic theory for Diks and Panchenko (2006) test. Ajmi et al. (2015), investigated the dynamics of causal link between exports and economic growth by utilizing both linear and nonlinear Granger causality tests. With the linear Granger causality, their study revealed no significant evidence of the causal relationship between exports and GDP. By using Hiemstra and Jones (1994) and Diks and Panchenko (2006), both tests led to misleading conclusions based on the standard linear Granger causality tests which neither accounts for structural breaks nor uncover nonlinearities in the dynamic relationship between the variables.With Hiemstra and Jones test, a unidirectional causality relationship was recorded while Diks and Panchenko revealed a significant bi-directional causality. For more reading causality also see Nazlioglu et al (2014), Bal and Rath (2015) and Phiri (2016).

\section{Methodology}

This study integrates two methods which include testing no cointegration null hypothesis against the threshold cointegration through TEVM model and nonlinear causal relationship. 
Preliminary analysis: Discussed in this section are the methods for preparing the data for empirical analyses. The results obtained here aremeant to give guidance about the nature of the data and the type of models to estimate.

Nonlinearity test: Prior estimation of the models, the nonlinear test which includes the Ramsey RESET test is established. The RESET test is a detailed test for linear regression analysis. With regards to the study, the normally utilized linear regression model is the univariate autoregressive model of order p, denoted by AR (p).The RESETtest was derived by Ramsey (1969) as follows:

$$
\mathrm{Y}_{\mathrm{t}}=\beta_{0}+\sum_{\mathrm{j}=1}^{\mathrm{p}} \beta_{\mathrm{j}} \mathrm{Y}_{\mathrm{t}-\mathrm{p}}+\varepsilon_{\mathrm{t}}
$$

where $\beta_{0}, \beta_{1}, \ldots, \beta_{\mathrm{p}}$ are the estimated parameters of the regression model and $\varepsilon_{\mathrm{t}} \sim \mathrm{i}$.i. $\mathrm{d}\left(\mu, \sigma_{\varepsilon}^{2}\right)$. In order to practically achieve a minimum error, Franses and Van Dijk (2000)stated that the value of p must be selected in such a way that it minimizes information criterions.

If $Y_{t}=\left(Y_{t-1}, Y_{t-2}, \ldots, Y_{t-p}\right)$ then (1) becomes:

$$
Y_{t}=Y_{t}^{\prime} \beta+\varepsilon_{t} .
$$

Moreover, (2) can be generalizedin the following manner as Shumway and Stoffer (2010) has suggested:

This simplifies to:

$$
\mathrm{Y}_{\mathrm{t}}=\Phi\left(\Phi \mathrm{T}_{\mathrm{t}-2}+\varepsilon_{\mathrm{t}-1}\right)+\varepsilon_{\mathrm{t}} \text {. }
$$

Which when repeated $\mathrm{k}-1$ times, (4) becomes:

$$
\mathrm{Y}_{\mathrm{t}}=\varepsilon_{\mathrm{t}}+\Phi \varepsilon_{\mathrm{t}-1} \Phi^{2} \mathrm{Y}_{\mathrm{t}-2}
$$

$$
\mathrm{Y}_{\mathrm{t}}=\varepsilon_{\mathrm{t}}+\Phi \varepsilon_{\mathrm{t}-1}+\Phi^{2} \varepsilon_{\mathrm{t}-2}+\cdots+\Phi^{\mathrm{k}-1} \varepsilon_{\mathrm{t}-\mathrm{k}+1}+\Phi^{\mathrm{k}} \mathrm{Y}_{\mathrm{t}-\mathrm{k}}
$$

Instead of modelling the errors as heavily tailed, it is possible to use a continuous mixture such as $t$ distribution. The RESET test involves, first, obtaining the OLS estimate, $\beta$ in equation (5), the residual $\hat{\varepsilon}_{t}=Y_{t}-$ $\widehat{Y}_{t}$, and the sum of squared residuals:

$$
\operatorname{SSR}_{0}=\sum_{\mathrm{t}=\mathrm{p}+1}^{\mathrm{n}} \widehat{\varepsilon}_{\mathrm{t}}^{2} .
$$

The second step is estimating the following regression:

$$
\hat{\varepsilon}_{\mathrm{t}}=\mathrm{Y}_{\mathrm{t}-1}^{\prime} \lambda_{1}+\mathrm{M}_{\mathrm{t}-1}^{\prime} \lambda_{2}+\mathrm{e}_{\mathrm{t}}
$$

Where $M_{t-1}^{\prime}=\left(\widehat{Y}_{t}^{2} Y_{t}^{3} \ldots Y_{t}^{s+1}\right)$ for $s>1, e_{t} \sim$ i.i. $d\left(\mu, \sigma_{e}^{2}\right)$. The sum of squared residuals from the estimated residuals of $\hat{\varepsilon}_{\mathrm{t}}=\hat{\varepsilon}_{\mathrm{t}}-\hat{\hat{\varepsilon}}_{\mathrm{t}}$ is computed as:

$$
\operatorname{SSR}_{1}=\sum_{\mathrm{t}=\mathrm{p}+1}^{\mathrm{n}} \hat{\mathrm{e}}_{\mathrm{t}}^{2} .
$$

Note that if the underlying $\operatorname{AR}(p)$ is adequate, the RESET test asserts that $\lambda_{1}$ and $\lambda_{2}$ are zero hence, the following hypothesis is tested:

$$
\begin{aligned}
& \mathrm{H}_{0}: \lambda_{\mathrm{ij}}=0 \\
& \mathrm{H}_{\mathrm{a}}: \lambda_{\mathrm{ij}} \neq 0
\end{aligned}
$$

The test statistic used for testing the hypothesis is the usual regression $\mathrm{F}$ statistic given as:

$$
\mathrm{F}=\frac{\mathrm{SSR} / \mathrm{p}-1}{\mathrm{SSE} / \mathrm{n}-\mathrm{p}} \sim \mathrm{F}_{\alpha, \mathrm{p}-1, \mathrm{n}-\mathrm{p}} \text {. }
$$

In this case, the null hypothesis of linearity is rejected if the calculated probability value of $\mathrm{F}$ statistic is less than the observed probability value. This implies that the true model specification is nonlinear, allowing the implementation of the proposed methods for the current study.

Testing the linear no cointegration null in a TVECM: This study uses methods that conform to the analysis of time series data.Time series analysis contains procedures for analyzing time series data keeping in mind the end goal to separate important measurements and different attributes of the data. As per Jonathan and Kung-Sik (2008), the motivation behind time series analysis is by and large twofold: (1) to comprehend the stochastic mechanism that offers ascend to an observed series and (2) to forecast the future values of a series in light of the historical backdrop of that series and perhaps, other related series. The review of TVECM in this section is motivated by Lo and Zivot (2001) who suggested the following equation:

$$
\Phi(\mathrm{L}) \Delta \mathrm{x}_{\mathrm{t}}=\alpha_{1} \mathrm{z}_{\mathrm{t}-1} 1\left\{\mathrm{z}_{\mathrm{t}-1} \leq \gamma_{1}\right\}+\alpha_{2} \mathrm{z}_{\mathrm{t}-1} 1\left\{\mathrm{z}_{\mathrm{t}-1}>\gamma_{2}\right\}+\mu+\varepsilon_{\mathrm{t}}
$$

where $t=1,2,3, \ldots, n$ and $q^{\text {th }}$ order polynomial in the lag operator is denoted by $\Phi(\mathrm{L})$ which can be extended to be $\Phi(\mathrm{L})=\mathrm{I}-\Phi_{1} \mathrm{~L}^{1}-\cdots-\Phi_{\mathrm{q}} \mathrm{L}^{\mathrm{q}}$. The error correction term is defined as $\mathrm{z}_{\mathrm{t}}=\mathrm{x}_{\mathrm{t}}^{\prime} \beta$ for a known cointegrating vector $\beta$. The threshold parameter $\gamma=\left(\gamma_{1}, \gamma_{2}\right)$ which satisfy the following condition $\gamma_{1} \leq \gamma_{2}$ and takes values on a compact set $\Gamma$ is estimated. Equation (10) does not allow any adjustment region in between $\gamma_{1}<\mathrm{z}_{\mathrm{t}-1} \leq$ 
$\gamma_{2}$ which arises due to the presence of transaction barriers or policy interventions. We employ this model because it has been used in most empirical studies often with restrictions, such as $\alpha_{1}=\alpha_{2}$ and or $\gamma_{1}=a \gamma_{2}$ imposed. The testing approach developed in this paper can be applied to restricted models with little modification. There are four possible hypotheses as Seo (2006) has indicated.Hansen and Seo (2002) developed a test for the linear cointegration null hypothesis in a two-regime TVECM. In other words, they test the hypothesis $\alpha_{1}=\alpha_{2}$ under the restriction that both are nonzero, and that $\gamma_{1}=\gamma_{2}$. Following the convention in the literature, it is assumed throughout this paper that there is no such case as threshold no cointegration. Nevertheless, Seo (2006)suggested that future studies should develop a test for the threshold no cointegration null hypothesis as the parameter space for the threshold no cointegration hypothesis is quite complicated i.e a subset of $\left\{\alpha_{1}=0\right.$ and $\left.\alpha_{2}=0\right\}$ or $\left\{\alpha_{1} \neq 0\right.$ and $\left.\alpha_{2}=0\right\}$,since the intercept $\mu$ also plays a role in determining the stationarity of the error correction term $z_{\mathrm{t}}$.

Estimation of a Threshold parameter: Since the stationary distribution of a TVECM model does not have a closed form solution, Jonathan and Kung-Sik (2008) revealed that the estimation is often carried out conditional on the $\max (\mathrm{p}, \mathrm{d})$ initial values where $\mathrm{p}$ is the order process and $\mathrm{d}$ is the delay parameter. According to Chan and Kutoyants (2012), the threshold parameter denoted by $\gamma \in \Theta=(\alpha, \beta)$ which is unknown threshold parameter. The goal is to estimate $\gamma$ from observations $X^{n}=\left(X_{0}, X_{1}, \ldots, X_{n}\right)$. Therefore, using the maximum likelihood estimator to estimate the threshold parameter, the likelihood function according to Chan and Kutoyants (2012) is as follows:

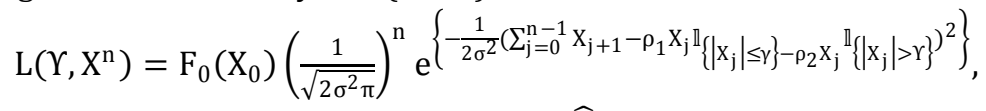

and the maximum likelihood estimator (MLE) $\widehat{\Upsilon}$ is defined by the equation:

$$
\frac{S U P L}{r, X^{n}}\left(\gamma, \mathrm{X}^{\mathrm{n}}\right)=\operatorname{Max}\left[\mathrm{L}\left(\hat{\gamma}_{\mathrm{n}}+\mathrm{X}^{\mathrm{n}}\right), \hat{\gamma}_{\mathrm{n}}-\mathrm{X}^{\mathrm{n}}\right]
$$

If this equation has many solutions, we can, for example, call the MLE to be the value which is at the center of the gravity.

The Nonparametric Diks-Panchenko Causality Test: Granger proposed a causality test to portray the reliance relations between economic time series. As per this, if two variables $\left\{X_{t}, Y_{t} \geq 1\right\}$ are strictly stationary, $\left\{Y_{t}\right\}$ Granger causes $\left\{X_{t}\right\}$ if past and current values of $X_{t}$ contain additional information on future values of $Y_{t}$. Suppose $F_{X t}$ and $F_{Y t}$ denote the information sets consisting of past observations of $X_{t}$ and $Y_{t}$ for time $t$, then, $\left\{Y_{t}\right\}$ Granger causes $\left\{X_{t}\right\}$ if:

$$
\left(\mathrm{Y}_{\mathrm{t}+1}, \ldots, \mathrm{Y}_{\mathrm{t}+\mathrm{k}}\right)\left|\left(\mathrm{F}_{\mathrm{X}, \mathrm{t}}, \mathrm{F}_{\mathrm{Y}, \mathrm{t}}\right) \sim \mathrm{Y}_{\mathrm{t}+1}, \ldots, \mathrm{Y}_{\mathrm{t}+\mathrm{k}}\right| \mathrm{F}_{\mathrm{X}, \mathrm{t}},
$$

$\mathrm{k} \geq 1$ in this case. However, in practice $\mathrm{k}=1$ is more often than used. Nevertheless, Granger non-causality can be tested by comparing the one-step-ahead conditional distribution of $\left\{\mathrm{Y}_{\mathrm{t}}\right\}$ with and without past and current observed values of $\left\{\mathrm{X}_{\mathrm{t}}\right\}$. To test for Granger causality, we consider a two stationary time series with a meanmodelE $\left(\mathrm{Y}_{\mathrm{t}+1} \mid\left(\mathrm{F}_{\mathrm{X}, \mathrm{t}}, \mathrm{F}_{\mathrm{Y}, \mathrm{t}}\right)\right)$. We compute the residuals of a fitted TVECM. Suppose that $\mathrm{X}_{\mathrm{t}}^{\ell \mathrm{X}}=\left(\mathrm{X}_{\mathrm{t}-\ell \mathrm{X}+1}, \ldots, \mathrm{X}_{\mathrm{t}}\right)$ and $\mathrm{Y}_{\mathrm{t}}^{\ell \mathrm{Y}}=\left(\mathrm{Y}_{\mathrm{t}-\ell \mathrm{Y}+1}, \ldots, \mathrm{Y}_{\mathrm{t}}\right)$ are the delay vectors where $\ell_{\mathrm{X}}, \ell_{\mathrm{Y}} \geq 1$. The null hypothesis to be tested is:

$$
\mathrm{H}_{0}: \mathrm{Y}_{\mathrm{t}+1}\left|\left(\mathrm{X}_{\mathrm{t}}^{\ell_{\mathrm{X}}} ; \mathrm{Y}_{\mathrm{t}}^{\ell} \mathrm{Y}\right) \sim \mathrm{Y}_{\mathrm{t}+1}\right| \mathrm{Y}_{\mathrm{t}}^{\ell_{\mathrm{Y}}} .
$$

The null hypothesis becomes a statement about the invariant distribution of the $\left(\ell_{\mathrm{X}}+\ell_{\mathrm{Y}}+1\right)$-dimensional vector $\mathrm{W}_{\mathrm{t}}=\left(\mathrm{X}_{\mathrm{t}}^{\ell_{\mathrm{x}}}, \mathrm{Y}_{\mathrm{t}}^{\ell_{\mathrm{X}}}, \mathrm{Z}_{\mathrm{t}}\right)$. Ignoring the time index and if $\ell_{\mathrm{X}}=\ell_{\mathrm{Y}}=1$, the $\mathrm{t}$ distribution of $\mathrm{Z}$ given that $(\mathrm{X}, \mathrm{Y})=(\mathrm{x}, \mathrm{y})$ is the same as of $\mathrm{Z}$ given $\mathrm{Y}=\mathrm{y}$ respectively. Nonetheless, in order to take account of the ratios of the joint distributions, [15] is restructured (Karagianni et al., 2013). In that sense, the joint probability density function $\mathrm{F}_{\mathrm{X}, \mathrm{Y}, \mathrm{Z}}(\mathrm{X}, \mathrm{y}, \mathrm{z})$ and its marginals should satisfy the following relationship:

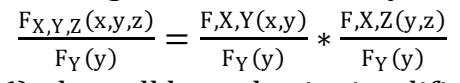

As per Diks and Panchenko (2006), the null hypothesis simplifies to:

$$
\mathrm{q} \equiv \mathrm{E}\left[\mathrm{F}_{\mathrm{X}, \mathrm{Y}, \mathrm{Z}}(\mathrm{X}, \mathrm{Y}, \mathrm{Z}) \mathrm{F}_{\mathrm{Y}}(\mathrm{Y})-\mathrm{F}_{\mathrm{X}, \mathrm{Y}}(\mathrm{X}, \mathrm{Y}) \mathrm{F}_{\mathrm{Y}, \mathrm{Z}}(\mathrm{Y}, \mathrm{Z})\right]=0 .
$$

Then, the test statistic is a scaled sample version of $q$ in equation (17):

$$
\mathrm{T}_{\mathrm{n}}\left(\varepsilon_{\mathrm{n}}\right)=\frac{\mathrm{n}-1}{\mathrm{n}(\mathrm{n}-2)} * \sum_{\mathrm{i}}\left(\hat{\mathrm{f}}_{\mathrm{X}, \mathrm{Y}, \mathrm{Z}}\left(\mathrm{X}_{\mathrm{i}}, \mathrm{Y}_{\mathrm{i}}, \mathrm{Z}_{\mathrm{i}}\right) \hat{\mathrm{f}}_{\mathrm{Y}}\left(\mathrm{Y}_{\mathrm{i}}\right)-\hat{\mathrm{f}}_{\mathrm{X}, \mathrm{Y}}\left(\mathrm{X}_{\mathrm{i}}, \mathrm{Y}_{\mathrm{i}}\right) \hat{\mathrm{f}}_{\mathrm{Y}, \mathrm{Z}}\left(\mathrm{Y}_{\mathrm{i}}, \mathrm{Z}_{\mathrm{i}}\right)\right)
$$


for $\ell_{\mathrm{X}}=\ell_{\mathrm{Y}}=1$, and if $\varepsilon_{\mathrm{n}}=\mathrm{C}_{\mathrm{n}}^{-\beta}\left(\mathrm{C}>0, \frac{1}{4}<\beta<\frac{1}{3}\right)$,therefore Diks and Panchenko (2006)attested that the test statistic in [18] satisfies the following condition:

$$
\sqrt{\mathrm{n}} \frac{\left(T_{\mathrm{n}}\left(\varepsilon_{\mathrm{n}}\right)-\mathrm{q}\right) \stackrel{\mathrm{D}}{\rightarrow} \mathrm{N}(0,1)}{\mathrm{S}_{\mathrm{n}}}
$$

$\stackrel{D}{\rightarrow}$ denotes convergence in distribution and $S_{n} s$ an estimator of the asymptotic variance of $T_{n}($.$) (Karagianni et$ al., 2013).In this study, the Karagianni's suggestion, to implement a one-tailed version of the test, has been employed. The null hypothesis is rejected if the observed probability value is greater than the critical probability value.

Empirical Analysis: Data for the period of January 2002 to March 2016 accessed from the South African Reserve bank(SARB) database is used.The intention of the study is to confirm the relationship between inflation rates and repo rates using the novel TVECM and nonlinear causality test. Makatjane and Moroke (2016) has emphasized the significance of assessing data behavior patterns prior model data analysis. This helps in identifying the properties associated with the data at hand and to help decide on the type of model to estimate.

Figure 1: South Africa Inflation Rate and Repo Rate

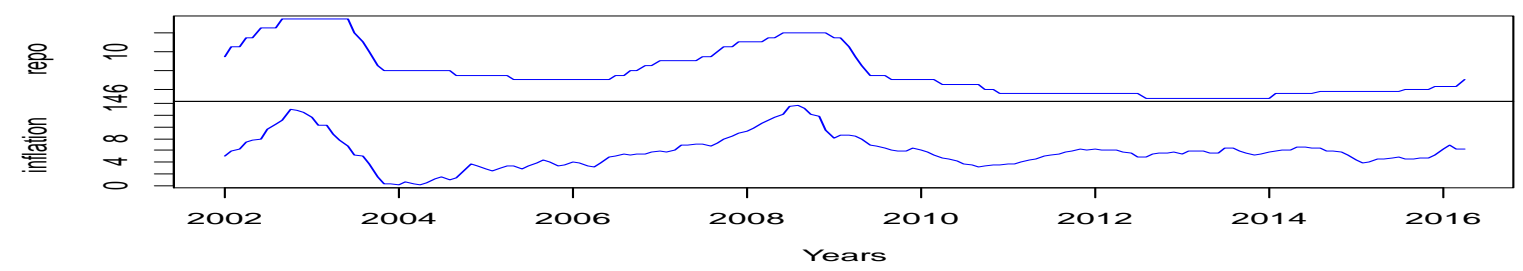

The co-movement between the inflation rate and repo rate is depicted in Figure 1. This serves as a strong motivation to use these variables with the proposed methods. Since the movements of the series from the year 2002 suggest the possibility of cointegration prior to imposing the transformation to the data. The up and down movement is an indication of volatility and this is expected for financial and macroeconomic time series. These series are as a result perfectly suitable to serve as experimental units for this study.They perfectly fit the proposed frameworks.

\section{Results}

Prior TVECM estimation, we used Ramsey reset test to confirm the null hypothesis of linearity against nonlinearity in the variables. The results of a RESET test are presented in Table 1.

Table 1: Estimated AR(1) models with nonlinear test

\begin{tabular}{lllll}
\hline Repo Rate & & & & \\
\hline Parameter & Coefficient & Std. Error & Test Statistic & Prob \\
$\mathrm{C}$ & 65.676 & 0.5271 & 14.532 & 0.00000 \\
$\Phi_{2}$ & 3.229 & 0.0803 & 0.109 & 0.00000 \\
Reset Test & 208.53 & & & 0.00000 \\
Inflation Rate & & & & \\
$\mathrm{C}$ & 6.6025 & 0.4549 & 14.512 & 0.00000 \\
$\Phi_{2}$ & -0.0065 & 0.0598 & -0.109 & 0.00000 \\
Reset Test & 25.509 & & & 0.00000 \\
\hline
\end{tabular}

It is evident in Table 1 that both the inflation and repo rate are nonlinear. The RESET test statistic is significant at $1 \%, 5 \%$ and even $10 \%$. This implies that the data is suitable for implementation of the nonlinear models. 
TVECM model and Threshold cointegration test: This section presents the results for a threshold cointegration method as summarized in Table 2. TVECM serves as the build on the Johansen cointegration framework. Ghassan and Banerjee (2015) opined that the Johansen procedure only assumes that the cointegrating vector remains constant during the sample period. This could be misleading owing to the scientific progress, transformation in people's preference, economic crisis, policy or regime alteration and institutional development. Such limitations are also valid for the Engel Granger method. Therefore, an enhanced Johansen cointegration framework is more appropriate for the current study as it also accommodates data with structural breaks. Table 2 reports the results from the TVECM.

Table 2: TVECM (1) model

\begin{tabular}{lll}
\hline $\begin{array}{l}\text { Lower Regime } \\
\text { Parameter }\end{array}$ & Estimate \\
\hline & $\delta_{1}$ & $-0.0117(0.0100)^{*}$ \\
& $\mu_{1}$ & $0.0089(0.6860)$ \\
& $\Phi_{11}$ & $0.2150(0.0079)^{* *}$ \\
& $\Phi_{21}$ & $0.4317(0.000)^{* * *}$ \\
Upper Regime & & \\
& $\delta_{2}$ & $-0.5463(0.0005)^{* * *}$ \\
& $\mu_{2}$ & $-3.7823(0.0006)^{* * *}$ \\
& $\Phi_{12}$ & $-0.4156(0.0456)^{*}$ \\
& $\Phi_{22}$ & $0.4804(0.0001)^{* * *}$ \\
\hline
\end{tabular}

Notes ${ }^{* * *}$ significant @ 1\% ** significant at 5\%, *significant at 10\%; Numbers in () are standard errors

Applying equation 16-17, the procedure yields a threshold parameter of $\gamma=0.119$. Based on this parameter the TVECM (1) is divided into two regimes. Regime 1 is defined by those monthly inflation rates were the absolute deviation from the long-term equilibrium is below $11.9 \%$. For every observation in regime 2 , the absolute deviation from the long-term equilibrium is above $11.9 \%$.UsingSeo (2006)'s supremum Wald statistic (herein referred to as supW in Table 3)bootstrapping50 replications, we find the critical threshold to be significant at $5 \%$. The test statistic is greater than the critical value 99.072 . We conclude that there is a threshold cointegration between the inflation rate and repo rate.

Table 3: Seo SupW bootstrap Test

\begin{tabular}{cll}
\hline Seo's threshold test & Test Statistic & Critical Value \\
\hline supW test & 104.0395 & 99.07157 \\
\hline
\end{tabular}

Diks-Panchenko Causality Test: Since the estimated TVECM(1) confirmed the presence of threshold cointegration between the variables, this also is an indication of the presence of short-run nonlinear relationship. A follow-up nonlinear causality test results are presented in Table 4.

Table 4: Diks-Panchenko nonparametric causality test

\begin{tabular}{ll}
\hline Group & Diks-Panchenko -test \\
\hline Inflation & {$[4.826]^{* * *}$} \\
Repo & {$[6.4918]^{* * *}$} \\
\hline Notes ${ }^{* * *}$ significant @ 1\% ${ }^{* *}$ significant at $5 \%,{ }^{*}$ significant at $10 \% ;$ Numbers in [] are nonparametric $t$ statistic
\end{tabular}

The results obtained from the test indicate a bidirectional causality between inflation rate and the repo rate inflation rate and the repo rate. The results imply that the use of repo rate to target the inflation rate during the target period did not address the problem in South Africa. The same findings were reported by BongaBonga and Kabundi (2015) in their study of monetary policy instrument and inflation in South Africa(Rossouw et al., 2014).Any change to the monetary sector affects short-term liquidity in the monetary 
system, which suddenly has an effect on other rates.Mboweni et al. (2008)and Gupta and Komen (2009)reported that a positive shock in the repo rate increase prices for more than 18 months giving no hope for prices to decrease after a positive monetary shock.

\section{Conclusion and Recommendations}

The current study aims to empirically investigate the threshold cointegration and nonlinear Granger causal relationships between inflation rate and repo rate of South Africa. Threshold cointegration was estimated through the TVECM. According to Ghassan and Banerjee (2015), TVECM serves as the extension of the Johansen cointegration framework which assumes that the cointegration vector is constant over a sampled period. The Johansen framework is unfounded in this instance due to structural changes in the economy. An estimated TVEM (1) was found to be a good framework for inflation and repo rates nexus. This was confirmed with an observed SupW test which was significant at all conventional levels of significance. Yau and Nieh (2009)reported similar studies in the context of Japan and Taiwan. Additionally, Diks-Panchenko Causality test confirmed a nonlinear a bidirectional causal relationship between the two variables. This implies that the nonlinear Granger causality test does not support the neutrality hypothesis of unidirectional relationship between inflation rate and repo rate of South Africa.This implies that repo rate may not to be a good instrument to control the inflation rates. Changes in the repo rate tend to have similar effects the inflation rate. See studies by Mboweni et al. (2008); Gupta and Komen (2009); and Bonga-Bonga and Kabundi (2015). This study provides some practical information to the SARB and decision makers for the use of repo rate and consumer consumption behavior policies. In this regard, decision makers would benefit from the findings for their policy implementations and in the economic planning process. For instance, they may take electricity consumption into account in policy designs by considering no aftermath effect of repo rate on inflation rate in South Africa. Furthermore, the monetary committee may implement the policies that aim at protecting the economy by considering other measures of the inflation as to target the inflation in the specified interval of 3\%-6\%.

\section{References}

Adusei, M. (2012). The inflation-growth nexus: estimating the threshold effect for South Africa. Journal of Money, Investment and Banking, 26, 87-93.

Ajmi, A. N., Aye, G. C., Balcilar, M. \& Gupta, R. (2015). Causality between exports and economic growth in South Africa: Evidence from linear and nonlinear tests. The Journal of Developing Areas, 49(2), 163-181.

Bal, D. P. \& Rath, B. N. (2015). Nonlinear causality between crude oil price and exchange rate: A comparative study of China and India. Energy Economics, 51, 149-156.

Balke, N. S. \& Fomby, T. B. (1997). Threshold cointegration. International economic review, 2, 627-645.

Baum, C. F., Barkoulas, J. T. \& Caglayan, M. (2001). Nonlinear adjustment to purchasing power parity in the post-Bretton Woods era. Journal of International Money and Finance, 20(3), 379-399.

Bonga-Bonga, L. \& Kabundi, A. (2015). Monetary policy instrument and inflation in South Africa: Structural vector error correction model approach.

Chan, N. H. \& Kutoyants, Y. A. (2012). On parameter estimation of threshold autoregressive models. Statistical inference for stochastic processes, 15(1), 81-104.

Chiou-Wei, S. Z., Chen, C. F. \& Zhu, Z. (2008). Economic growth and energy consumption revisited-evidence from linear and nonlinear Granger causality. Energy Economics, 30(6), 3063-3076.

Diks, C. \& Panchenko, V. (2006). A new statistic and practical guidelines for nonparametric Granger causality testing. Journal of Economic Dynamics and Control, 30(9), 1647-1669.

Diks, C. \& Wolski, M. (2015). Nonlinear granger causality: Guidelines for multivariate analysis. Journal of Applied Econometrics, 4(1).

Enders, W. \& Siklos, P. L. (2001). Cointegration and threshold adjustment. Journal of Business \& Economic Statistics, 19(2), 166-176.

Esso, L. J. (2010). Threshold cointegration and causality relationship between energy use and growth in seven African countries. Energy Economics, 32(6), 1383-1391, 11//.

Franses, P. H. \& Van Dijk, D. (2000). Non-linear time series models in empirical finance. Cambridge University Press. 
Ghassan, H. B. \& Banerjee, P. K. (2015). A threshold cointegration analysis of asymmetric adjustment of OPEC and non-OPEC monthly crude oil prices. Empirical Economics, 49(1), 305-323.

Ghosh, S. \& Kanjilal, K. (2016). Co-movement of international crude oil price and Indian stock market: Evidences from nonlinear cointegration tests. Energy Economics, 53, 111-117.

Granger, C. W. J. \& Lee, T. H. (1989). Investigation of production, sales and inventory relationships using multicointegration and non-symmetric error correction models. Journal of applied econometrics, 4 (S1), S145-S159.

Gupta, R. \& Komen, K. (2009). Time aggregation and the contradictions with causal relationships: can economic theory come to the rescue? University of Pretoria, Pretoria, 0002.

Hansen, B. E. \& Seo, B. (2002). Testing for two-regime threshold cointegration in vector error-correction models. Journal of Econometrics, 110(2), 293-318.

Hiemstra, C. \& Jones, J. D. (1994). Testing for linear and nonlinear Granger causality in the stock price-volume relation. The Journal of Finance, 49(5), 1639-1664.

Iyke, B. N. (2015). On the term structure of South African interest rates: Cointegration and threshold adjustment.

Jonathan, D. \& Kung-Sik, C. (2008). Time Series Analysis With Applications in R. New York: Springer Science and Business Media , LLC.

Karagianni, S., Pempetzoglou, M. \& Saraidaris, A. P. (2013). Average tax rates and economic growth: A nonlinear causality investigation for the USA. Frontiers in Finance and Economics, 12(1), 51-59.

Leshoro, T. L. (2012). Estimating the inflation threshold for South Africa. Studies in Economics and Econometrics, 36(2), 53-65.

Lo, M. C. \& Zivot, E. (2001). Threshold cointegration and nonlinear adjustment to the law of one price. Macroeconomic Dynamics, 5(04), 533-576.

Makatjane, K. D. \& Moroke, N. D. (2016). Comparative Study of Holt-Winters Triple Exponential Smoothing and Seasonal Arima: Forecasting Short Term Seasonal Car Sales in South Africa. Risk governance \& control: financial markets \& institutions, 6(1).

Mboweni, T., Cross, M. J., Thahane, M. T., Marcus, M. G., van der Merwe, E., \& Wiese, M. C. (2008). Statement of the Monetary Policy Committee. South African Reserve Bank, December, 6.

Nazlioglu, S., Kayhan, S. \& Adiguzel, U. (2014). Electricity consumption and economic growth in Turkey: cointegration, linear and nonlinear granger causality. Energy Sources, Part B: Economics, Planning, and Policy, 9(4), 315-324.

Phiri, A. (2016). Tourism and economic growth in South Africa: Evidence from linear and nonlinear cointegration frameworks. Managing Global Transitions, 14(1), 31.

Ramsey, J. B. (1969). Tests for specification errors in classical linear least-squares regression analysis. Journal of the Royal Statistical Society. Series B (Methodological), 350-371.

Rossouw, J., Vermeulen, J. \& Leshoro, L. (2014). Monetary Economics in South Africa. OUP Catalogue.

Seo, M. (2006). Bootstrap testing for the null of no cointegration in a threshold vector error correction model. Journal of Econometrics, 134(1), 129-150.

Shumway, R. H. \& Stoffer, D. S. (2010). Time series analysis and its applications: with R examples. Springer Science \& Business Media.

Stigler, M. (2010). Threshold cointegration: overview and implementation in R: Working paper.

Taylor, A. M. (2001). Potential pitfalls for the purchasing-power-parity puzzle? Sampling and specification biases in mean-reversion tests of the law of one price. Econometrica, 69(2), 473-498.

Yau, H. Y. \& Nieh, C. C. (2009). Testing for cointegration with threshold effect between stock prices and exchange rates in Japan and Taiwan. Japan and the World Economy, 21(3), 292-300. 